\title{
Emotion Recognition using Facial Thermal Images
}

\author{
Jin-Sup Eom, Jin-Hun Sohn \\ Department of Psychology/Brain Research Institute, Chungnam National University, Daejeon, 305-765
}

\begin{abstract}
Objective: The aim of this study is to investigate facial temperature changes induced by facial expression and emotional state in order to recognize a persons emotion using facial thermal images. Background: Facial thermal images have two advantages compared to visual images. Firstly, facial temperature measured by thermal camera does not depend on skin color, darkness, and lighting condition. Secondly, facial thermal images are changed not only by facial expression but also emotional state. To our knowledge, there is no study to concurrently investigate these two sources of facial temperature changes. Method: 231 students participated in the experiment. Four kinds of stimuli inducing anger, fear, boredom, and neutral were presented to participants and the facial temperatures were measured by an infrared camera. Each stimulus consisted of baseline and emotion period. Baseline period lasted during $1 \mathrm{~min}$ and emotion period 1 3min. In the data analysis, the temperature differences between the baseline and emotion state were analyzed. Eyes, mouth, and glabella were selected for facial expression features, and forehead, nose, cheeks were selected for emotional state features. Results: The temperatures of eyes, mouth, glanella, forehead, and nose area were significantly decreased during the emotional experience and the changes were significantly different by the kind of emotion. The result of linear discriminant analysis for emotion recognition showed that the correct classification percentage in four emotions was $62.7 \%$ when using both facial expression features and emotional state features. The accuracy was slightly but significantly decreased at $56.7 \%$ when using only facial expression features, and the accuracy was $40.2 \%$ when using only emotional state features. Conclusion: Facial expression features are essential in emotion recognition, but emotion state features are also important to classify the emotion. Application: The results of this study can be applied to human-computer interaction system in the work places or the automobiles.
\end{abstract}

Keywords: Emotion recognition, Thermal image, Facial expression, Physiological signal, Emotional state

\section{Introduction}

\author{
정서는 동기와 더불어 인간의 행동과 밀접한 관계가 있기 \\ 때문에, 최근 일과 일터에서의 정서에 대한 연구가 활발히 \\ 진행되고 있다(Fisher \& Ashkanasy, 2000). 정서와 일의 \\ 관련성에 관한 연구들이나, 정서와 운전행동에 관한 연구들 \\ 을 보면, 일반적으로 부정적인 정서는 안전하지 않은 행동을 \\ 하도록 만들며, 사고의 가능성을 증가시킨다고 보고하고 있
}

다(Arnett, Offer, \& Fine, 1997; Banuls, Carbonell Yaya, Casanoves, \& Chisvert, 1996; Chen, Z., Ma, L., \& Sen, Y., 2011; Deffenbacher, Lynch, Filetti, Dahlen, \& Oetting, 2003). 이러한 연구결과들은 위험한 일을 수행하는 작업자 들이나 운전자들의 정서를 실시간으로 파악해야 할 필요성 을 보여주고 있으며, 작업자나 자동차 운전자의 정서상태를 인식하려는 연구들이 진행되고 있다(Katsis, Katertsidis, Ganiatsas, \& Fotiadis, 2008; Loukidou, Loan-Clarke, \& Daniels, 2009; Nasoz, Alvarez, Lisetti, \& Finkelstein, 2004). 작업자나 운전자의 정서 인식은 실시간이며 지속적

Corresponding Author: Jin-Hun Sohn. Department of Psychology/Brain Research Institute, Chungnam National University, Daejeon, $305-765$.

Mobile: +82-10-9250-6369, E-mail: jhsohn@cnu.ac.kr

Copyright@2012 by Ergonomics Society of Korea(pISSN:1229-1684 eISSN:2093-8462 http://www.esk.or.kr). All right reserved.

(c) This is an open-access article distributed under the terms of the Creative Commons Attribution Non-Commercial License(http://creativecommons.org/licenses/by-nc/3.0/), which permits unrestricted non-commercial use, distribution, and reproduction in any medium, provided the original work is properly cited. 
으로 이루어져야 하기 때문에, 이와 관련된 연구들은 대부분 컴퓨터가 인간의 정서를 인식하도록 하는데 초점을 맞추고 있다.

컴퓨터가 인간의 정서를 인식하도록 하기 위해서는 인간 에게서 정서와 관련된 정보를 추출해야만 한다. 기존의 연구 들은 주로 세 가지 방법에 초점을 두어왔다. 첫 번째는 가장 많이 연구된 것으로 얼굴 표정으로부터 정서를 인식하는 것 이다. 이 방법은 동영상 카메라로 얻은 얼굴 이미지에 대해 얼굴 움직임 단위 (action units)의 변화나, 눈과 코, 입 등 에서의 변화, 또는 전체적인 얼굴패턴의 변화 등을 탐지한다 (Bartlett et al., 2006; Chang et al., 2006; Cohn, 2006). 동영상 카메라를 이용하여 정서를 파악하는 방법의 장점은 비접촉식으로 사용할 수 있으므로, 작업자나 운전자의 행동 에 큰 영향을 미치지 않는다는 점이다. 그러나 이 방법의 가 장 큰 단점은, 이 방법이 시각 이미지를 이용하기 때문에, 빛 의 양과 얼굴에 드리워진 그림자의 형태에 따라서 정서 인 식 정확도가 크게 달라진다는 점이다.

두 번째는 음성을 이용하여 정서를 인식하는 방법이다. 이 방법은 음성의 에너지(energy)나 피치(pitch), 포먼트 (formant), 리듬(rhythm) 등을 이용하여 정서를 파악하고 자 한다(Eyben et al., 2010; Morrison et al., 2007; Shami $\&$ Berhelst, 2007). 작업자나 운전자의 정서를 파악하기 위하여 음성을 이용하는 기법의 장점 역시, 비접촉식으로 사 용할 수 있다는 점이다. 이 방법의 가장 큰 단점은 작업자나 운전자가 말을 하기 전까지는 정서파악이 불가능하다는 점이 다. 그러나 작업장이나 운전상황에서 말을 하는 경우가 많지 않으므로, 이 방법을 효율성은 그리 높지 못할 것이다.

세 번째는 생리신호(physiological signal)를 이용하여 정 서를 인식하는 방법이다. 정서에 따라서 교감신경계와 부교 감신경계가 활성화되는 패턴이 달라진다고 가정하며, 교감신 경계와 부교감신경계의 지표가 되는 심장박동률(heart rate) 과 혈압(blood pressure), 피부전기반응 (electrodermal activity), 피부온도(skin temperature), 호흡률(respiratory rate) 을 이용하여 정서상태를 추론한다(Kim et al., 2004; Liu et al., 2008; Picard et al., 2001). 얼굴 표정에 대한 영상을 이용하는 방법은 관찰대상이 스스로의 표정을 숨길 수도 있지만, 생리신호를 이용하는 방법은 그것이 쉽지 않다 는 장점을 가진다. 이 장점이 거짓말 탐지에서 생리신호가 가장 많이 사용되는 이유이기도 하다. 그러나, 이 방법은 관 찰대상의 몸에 다양한 측정 센서를 부착해야 한다는 주요한 단점을 가지기도 한다.

최근에, 적외선 열영상 카메라(infrared thermography camera)를 이용한 정서인식 연구가 시작되고 있다(Liu \& Wang, 2011; Merla \& Romani, 2007; Rimm-Kaufman \& Kagan, 1996; Yoshitomi, 2010). 적외선 열영상 카메라는
피사체의 표면으로부터 방사되는 적외선 파장 형태의 에너 지를 검출하여 복사열의 강도를 추정한 후, 강도에 따라 서 로 다른 색상으로 표현하여 보여준다. 얼굴 표면 온도는 여 러 가지 이유로 서로 다르게 분포한다. 얼굴의 구성요소(눈, 입 등)에 따라 얼굴 표면 온도가 달라지며, 피부의 두께에 따라서도 온도가 달라진다. 또한 혈관은 다른 피부 조직에 비하여 온도가 높기 때문에, 혈관의 분포에 따라 얼굴 표면 온도가 달라진다. 열영상 카메라는 주변의 조도에 영향을 받지 않기 때문에, 동영상 카메라가 불빛에 전적으로 의존한 다는 단점을 극복할 수 있다.

얼굴 표면 온도와 정서상태 간의 관련에 관한 연구들은 크게 두 가지로 나누어진다. 한 가지는 근육의 움직임에 의 해 발생하는 얼굴 표정과 얼굴 표면 온도 간의 관련성으로 정서를 분류하고자 하는 연구들이다(Jarlier et al., 2011; Khan et al., 2006; Liu \& Wang, 2011; Trujillo et al., 2005; Yoshitomi, 2010). 이 연구들은 시각 영상 대신 열영상을 이용하여 정서를 인식하고자 하는 특징을 가지고 있으며, 대 부분은 실험참여자가 인위적으로 특정 정서의 얼굴 표정을 지은 후, 열영상 이미지를 분석하고 있으며, 소수의 연구만 이 실험참여자에게 정서를 직접 유발시켰다.

얼굴 표정에 의한 온도 변화는 주로 아래의 이유로 발생 한다. 눈에서의 온도 변화는 눈을 뜨거나 감을 때 발생한다. 안구의 온도가 눈꺼풀의 온도보다 낮게 측정되므로, 온도가 감소했다는 것은 눈을 더 크게 떴다는 것을 의미한다. 입에 서의 온도 변화는 입을 벌리거나 입을 다물 때 나타나는데, 입을 벌렸을 때, 입안의 빈 공간으로 인해 온도가 낮게 측정 된다. 미간에서의 온도 변화는 눈썹의 위치 변화에 의해 발 생한다. 눈썹의 온도가 피부의 온도보다 낮기 때문이다.

다른 한 가지는 얼굴 표정과는 무관하게 발생하는 얼굴 표 면 온도의 변화와 정서 간의 관련성을 탐구한 연구들이다 (Merla \& Romani, 2007; Nakanishi \& Imai-Matsumura, 2008; Nhan \& Chau, 2010; Kuraoka \& Nakamura, 2011; Rimm-Kaufman \& Kagan, 1996; Tsiamyrtzi et al., 2007). 혈관의 팽창과 수축이나 땀샘의 작용 등에 기인한 온도 변화 를 탐지하여 정서와의 관련성을 살펴본다. 이 범주의 연구들 은 한두 가지의 정서상태, 인지적 활동상태, 또는 각성상태 와 얼굴 표면 온도 간의 관련성을 연구하였으며, 주로 얼굴 의 일부 관심 영역(이마나 눈)에 대해서만 표면 온도를 분 석하고 있다.

열영상 카메라를 이용한 정서 인식이 주변의 밝기에 영향 을 받지 않는다는 장점 외에 한 가지 중요한 장점을 한 가지 더 가지고 있다. 그것은 앞에서 살펴보았듯이, 열영상 카메 라 한 가지만으로 근육의 움직임에 의한 얼굴 표정과 자율 신경계의 작용에 의한 생리신호(피부 온도)를 동시에 측정 할 수 있다는 점이다. 따라서, 이 두 가지를 동시에 이용하 
여 정서 인식에 활용한다면, 열영상을 이용한 정서 인식 절 차의 가치가 더욱 높아질 것이다. 그러나 아직까지 이 둘을 명백하게 구분하여 측정한 후, 정서 인식을 시도한 연구는 찾아볼 수 없다. 특히, 자율신경계의 작용에 의한 얼굴 온도 를 측정하기 위해서는 인위적인 얼굴 표정 유도방법이 아닌 자극에 의해 특정 정서를 유발시켜야만 한다.

본 연구에서는 얼굴 근육의 움직임에 의한 얼굴 온도 변 화와 혈관이나 땀샘 작용에 의한 온도 변화를 열영상 카메 라를 이용하여 측정하고, 이를 이용하여 대상자의 정서상태 를 분류하고자 하였다. 본 연구에서 분류하고자 한 정서는 일터와 운전상황에서 중요할 것이라고 생각되는 분노, 공포, 지루함, 중립 정서였다. 또한 본 연구에서는 인위적인 표정 이 아닌, 동영상과 시청각 자극 등의 다양한 방법으로 실험 참여자에게 목표 정서를 유발시키는 방법을 사용하였다.

\section{Method}

\subsection{Participants}

중학생과 고등학생, 대학생 300명이 실험에 자원하여 참여하였으며, 이들 중, 얼굴 영화상이 정상적으로 수집된 231 명의 자료를 분석하였다. 남자 101 명, 여자 130 명이었 으며, 평균 연령은 20.0세(범위 13 31세) 였다.

\subsection{Stimuli}

실험참여자에게 분노, 공포, 지루함, 중립 정서를 유발시 키기 위하여, TV 드라마와 영화, 사진 등의 다양한 시청각 자극을 사용하였다. 시청각 자극을 제시하기 전에 '+' 모양 의 자극을 컴퓨터 화면 중앙에 1 분 동안 제시하여, 실험참여 자들을 심리생리적으로 안정상태가 되도록 유도한 다음, 목 표 정서를 유발하기 위한 시청각 자극을 제시하였다. 정서 자 극의 길이는 Gross와 Levenson(1995)의 연구결과를 참고 하였으며, 정서에 따라 1 분에서 3 분 길이로 설정하였다. 분 노 유발 자극은 1 분 30 초 분량의 버스 안에 설치된 $\mathrm{CCTV}$ 동영상으로 승객이 버스기사를 폭행하는 장면이 담겨 있다. 공포는 2 분 분량의 동영상으로, 공포영화 '장화홍련' 중 귀 신이 나타나는 부분을 뽑아서 사용하였다. 지루함 유발 자극 은 3 분 분량의 시청각 자극으로 구성되어 있으며, 컴퓨터 화면에는 3 분 동안 '+' 모양의 자극이 제시되며, 단조로운 목소리로 2 초에 한번씩 1 에서부터 10 까지 세는 소리가 3 분 동안 반복된다. 중립은 1 분 분량의 시각 자극으로 구성되 어 있으며, 컴퓨터 화면에 의자 사진이 제시되었다. 실험참 여자에게 목표 정서가 유발되었는지 질문한 결과, 모든 정서
에서 $80 \%$ 이상의 응답자들이 목표 정서가 유발되었다고 응 답하였으며(지루함에서 $84.3 \%$ 로 가장 낮았으며, 중립에서 $94.8 \%$ 로 가장 높았다), 그 정서가 얼마나 강했는지를 7점 척도상에 응답하도록 한 결과, 평균 4.5 이상의 값을 보였다 (지루함에서 $\mathrm{M}=5.20, \mathrm{SD}=1.36$ 으로 가장 낮았고 분노 에서 $\mathrm{M}=6.06, \mathrm{SD}=1.01$ 로 가장 높았다).

\subsection{Experimental procedure}

실험참여자는 실험자로부터 실험에 대한 전반적인 설명을 들고 실험참가 동의서에 서명한 후에 실험에 참여하였다. 실 험참여자는 실험실로 안내되어 실험실 중앙에 놓인 의자에 편하게 앉아서, 다른 연구목적을 위하여 신체에 생체신호 측 정 센서를 붙이는 20분 동안 심리 생리적으로 이완할 수 있 는 시간을 가졌다. 실험 자극은 $\mathrm{LCD}$ 모니터를 통하여 제시 하였다. 얼굴 표면 온도의 기저선을 측정하기 위하여 각 정 서 유발 자극을 제시하기 전에 1 분 동안 '+' 자극을 제시하 였으며, 이어서 정서 유발 자극을 제시하였다. 열영상 카메 라는 실험참여자로부터 $1.1 \mathrm{~m}$ 앞에 설치하였으며, 기저선 구 간과 정서 유발 구간에서 실험참여자의 얼굴 표면 온도를 기록하였다. 각 정서 유발 자극을 제시한 후, 어떤 장면에서 가장 큰 강도의 정서를 경험하였는지 질문하였으며, 그 때의 정서가 무엇이었는지, 강도는 어느 정도였는지 질문하였다.

경험한 정서와 강도를 묻는 질문과 함께, 자극이 정서가 (valence) 차원과 각성 (arousal) 차원에서 어디에 위치하 는지를 $-4 \sim 4$ 점 척도상에 표시하게 하였다. 자극의 정서가 가 매우 불쾌하면 -4 점을, 매우 쾌하면 +4 점을 부여하도록 하였으며, 각성 차원은 매우 이완되면 -4 점을, 매우 각성되 면 +4 점을 부여하도록 하였다. 모든 실험참여자가 네 가지 의 정서 유발 자극을 모두 경험하였으며, 자극 제시 순서는 실험참여자 별로 역균형화시켰다.

\subsection{Experimental environment and equipment}

실험은 가로 $6 \mathrm{~m}$, 세로 $7.2 \mathrm{~m}$ 의 실험실 안에 마련된 가로 $3.3 \mathrm{~m}$, 세로 $5.4 \mathrm{~m}$ 의 생체반응 측정실에서 실시하였다. 실험 실 중앙에 실험참여자가 앉을 의자가 놓여 있으며, 의자로 부터 $1 \mathrm{~m}$ 앞에 LCD 모니터가 있으며, $\mathrm{LCD}$ 모니터 $10 \mathrm{~cm}$ 뒤에 열영상 카메라가 설치되어 있다. 의자로부터 $2 \mathrm{~m}$ 앞의 좌우에는 스피커(BR 1800, Britz, USA)가 놓여 있었다. 얼 굴 표면 온도는 H2640(NEC San-ei, Japan)을 이용하여 초당 5장의 속도로 측정하였다. H2640 열영상 카메라의 측정범위는 $20 \sim 60^{\circ} \mathrm{C}$ 이며, 해상도는 $640 \times 480$ pixel, 측정 파장은 $8 \sim 14 \mu \mathrm{m}$, 온도 분해능은 $0.06{ }^{\circ} \mathrm{C}$ 이다. 


\subsection{Analysis}

\subsubsection{Data selection}

231명의 참여자로부터 네 가지 자극에 대해 측정한 얼굴 열영상 중 351 개의 자료만 분석에 사용하였다. 정서 별로는 81 92개였다. 반복측정설계를 사용하였으므로, 자료의 수 가 924 개이어야 하지만, 몇 가지 이유로 자료의 손실이 발 생하였다. 첫째로 자극에 의해 목표 정서가 뜻대로 유발되지 않은 자료는 분석에서 제외하였고, 둘째로 실험실의 온도 변 화가 $0.5{ }^{\circ} \mathrm{C}$ 이상 있었던 자료를 분석에서 제외하였으며, 마 지막으로 네 가지 정서조건에 해당하는 자료의 수를 비슷하 게 맞추기 위하여 중립과 지루함의 자료들 중 일부를 무작위 로 제거하였다.

\subsubsection{Feature extraction}

얼굴 열영상을 이용한 정서 인식은 정서가 유발되었을 때 의 얼굴 온도 변화를 이용하였다. 온도 변화를 측정하기 위 하여, 각 정서조건에서 기저선 구간에 측정한 열영상 한 장 과 정서 구간에서 측정한 열영상 한 장을 추출하였다. 기저 선 열영상은 표정이 없고 입을 다물고 있는 열영상을 한 장 추출하였으며, 정서 열영상은 실험참여자가 가장 큰 정서를 경험하였다고 진술한 구간에서 한 장의 열영상을 추출하였다.

온도 변화량을 계산하기 위해서는 두 장의 열영상을 중첩 시켜야 한다. 얼굴 영상의 경우에는 영상이 비교적 뚜렷하여 컴퓨터 프로그램을 이용하여 얼굴의 각 특징들을 찾아내고 두 장의 영상을 중첩시킬 수 있지만, 얼굴 열영상의 경우에 는 영상이 상대적으로 흐리기 때문에 아직까지 효과적으로 얼굴 특징점을 찾는 프로그램이 개발되지 못하고 있다. 이 때문에, 두 장의 열영상에서 상대적 위치가 고정되어 있다고 가정할 수 있는 세 점(양쪽 눈과 코끝)을 선정하여 수작업으 로 위치를 표시한 다음, 세 점에 기초하여 두 장의 열영상을 중첩시킨 후 정서 열영상과 기저선 열영상 간의 온도차이를 계산하였다(Liu \& Wang, 2011).

본 연구의 목적에 맞추어, 얼굴 근육의 움직임에 의한 얼 굴 온도 변화와 생리상태의 변화에 의한 얼굴 온도 변화를 나누어 계산하였다.

얼굴 영상에서 정서 인식에 사용되는 얼굴 특징들은 주로 근육의 움직임이 강하게 나타나는 눈과 입, 눈썹 등이므로 (Zeng, Pantic, Roisman, \& Huang, 2009), 얼굴 열영상에 서도 눈과 입, 미간에서 온도를 추출하였다. 선행연구들에서 는 얼굴의 특정 영역(예, 입)에서의 온도 변화를 특징값으로 변환할 때, 이 영역을 더 작은 영역으로 나누어 각 영역에서 의 온도 변화값을 수량화시킨다(Liu \& Wang, 2011; Khan et al., 2006; Yoshitomi, 2010). 선행연구들에서는 관심 영 역을 다수의 작은 영역(각 픽셀 또는 얼굴전체에서 75 개
영역)으로 나누기 때문에, 차이 이미지를 산출하기 위한 두 장의 영상을 정확하게 매칭시키는 것이 중요하다. 그러나, 열영상의 해상도와 머리의 움직임 때문에 정확하게 매칭시 키는 것이 쉽지 않다. 따라서, 본 연구에서는 각 관심 영역 을 네 개의 영역으로만 세분하였다. Figure 1 과 같이 눈과 입, 미간의 중심점을 기준으로 4 등분(왼쪽 위, 오른쪽 위, 왼 쪽 아래, 오른쪽 아래)하여 평균 온도 변화량을 계산하였다.

생리상태의 변화에 의한 얼굴 온도 변화를 계산하기 위하 여, Figure 1과 같이 코와 이마, 뺨에서의 평균 온도 변화량 을 계산하였다. 결과적으로 총 20 곳의 온도 변화량이 얼굴 특징값 (오른쪽 눈 $\times 4$, 왼쪽 눈 $\times 4$, 입 $\times 4$, 미간 $\times 4$, 코, 이 마, 오른쪽 뺨, 왼쪽 뺨 영역의 온도 변화)을 구성하였다.

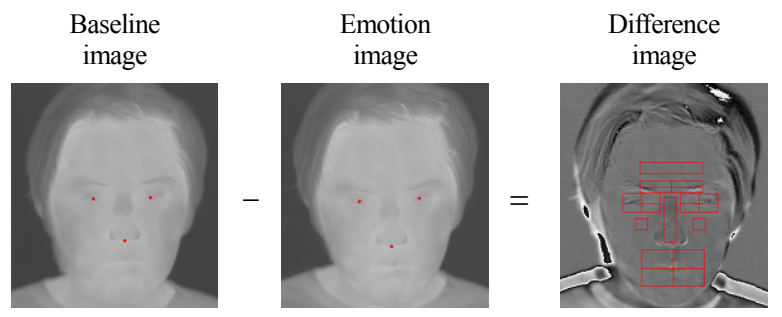

Figure 1. Thermal image and facial feature areas

\subsubsection{Statistical analysis}

각 정서에 대해, 얼굴 특징값들이 통계적으로 유의한지 검증하기 위하여 $\mathrm{t}$ 검증을 실시하였으며, 얼굴 특징값들이 네 가지 정서에 따라 차이가 있는지 검증하기 위하여 변량 분석(ANOVA)을 실시하였다. 얼굴 온도 변화량으로 네 가 지 정서가 구분 가능한지를 파악하기 위하여 선형판별분석 (linear discriminant analysis)을 실시하였다. 선형판별분석 은 세 번에 걸쳐서 실시하였다. 첫 번째는 눈과 입, 미간의 특징값만을 이용하였으며, 두 번째는 코와 이마, 뺨의 특징 값만을 이용하였으며, 세 번째는 얼굴의 모든 특징값을 이 용하였다.

\section{Results}

\subsection{Psychological responses}

본 연구에서 사용한 네 가지 자극의 특성을 정서의 2차원 모형상에서 파악하기 위하여, 각 자극의 정서가와 각성 수준 을 살펴보았다. Table 1 에 각 자극의 정서가와 각성 수준의 평균이 제시되어 있다. 변량분석 결과, 자극종류에 따라 정서 가가 다른 것으로 나타났는데, 분노가 가장 부정적이었으며 
$(\mathrm{M}=-3.68, \mathrm{SD}=0.61)$, 다음으로 공포가 부정적이었고 $(\mathrm{M}=-3.26, \mathrm{SD}=0.93)$, 지루함 $(\mathrm{M}=-1.32, \mathrm{SD}=1.27)$, 중립 $(\mathrm{M}=0.49, \mathrm{SD}=1.07)$ 순이었다. 각성 차원에서는 지 루함 $(\mathrm{M}=-1.90, \mathrm{SD}=1.83)$ 과 중립이 $(\mathrm{M}=-1.84, \mathrm{SD}=$ 1.17)이 비슷한 정도로 이완되는 것으로 평가되었으며, 분 노 $(\mathrm{M}=3.30, \mathrm{SD}=0.75)$ 와 공포 $(\mathrm{M}=3.35, \mathrm{SD}=0.76)$ 가 비슷한 정도로 매우 높게 각성되는 것으로 평가되었다.

Table 1. Valence and arousal of stimuli

\begin{tabular}{l|c|c}
\hline Emotion & Valence & Arousal \\
\hline Anger & $-3.68(0.61)$ & $3.30(0.75)$ \\
\hline Boredom & $-1.32(1.27)$ & $-1.90(1.83)$ \\
\hline Fear & $-3.26(0.93)$ & $3.35(0.76)$ \\
\hline Neutral & $0.49(1.07)$ & $-1.84(1.17)$ \\
\hline F & $324.811^{* * *}$ & $531.032^{* * *}$ \\
\hline Post Hoc & $1<3<2<4$ & $2,4<1,3$ \\
\hline
\end{tabular}

Note. Mean (standard deviation) ${ }^{* * *} p<.001$

\subsection{Facial thermal responses}

분노, 공포, 지루함, 중립조건 각각에 대하여, 기저선의 얼 굴 온도와 정서가 유발되었을 때의 얼굴 온도에 차이가 유의 한지 확인하기 위하여, 대응 $\mathrm{t}$-검증 (paired $\mathrm{t}$-test)을 수행 하였다. Table 2에 검증결과가 제시되어 있다. 분노 정서가 유발되었을 때에는 오른쪽 눈의 일부분(오른쪽 위 $p<.001$, 왼쪽 위 $p<.001$ ), 왼쪽 눈의 일부분(오른쪽 위 $p<.001$, 왼 쪽 위 $p<.05)$, 입(오른쪽 위, 왼쪽 위, 오른쪽 아래, 왼쪽 아 래 모두 $p<.001$ ), 미간의 아랫부분 (오른쪽 아래 $p<.001$, 왼쪽 아래 $p<.001)$, 코( $p<.05)$ 영역에서 유의한 온도 변화 가 나타났다. 기저선에 비하여 분노 정서가 유발되었을 때, 위 영역의 온도가 감소하였다.

지루함이 유발되었을 때에는 오른쪽 눈의 일부분(오른쪽 아래 $p<.01$, 왼쪽 아래 $p<.05$ ), 왼쪽 눈의 일부분(왼쪽 아 래 $p<.01$ ), 입의 일부분(왼쪽 아래, $p<.05$ ), 미간(오른쪽 위 $p<.05$, 왼쪽 위 $p<.05$, 오른쪽 아래 $p<.01$, 왼쪽 아래 $p<.01)$, 이마 $(p<.05)$, 코 $(p<.01)$ 영역에서 유의한 온도 변

Table 2. Facial temperature changes induced by emotional stimuli

\begin{tabular}{|c|c|c|c|c|c|c|c|}
\hline \multicolumn{2}{|c|}{ Feature } & $\begin{array}{l}\text { Anger (1) } \\
(\mathrm{n}=92)\end{array}$ & $\begin{array}{l}\text { Fear (2) } \\
(\mathrm{n}=81)\end{array}$ & $\begin{array}{c}\text { Boredom }(3) \\
(\mathrm{n}=90)\end{array}$ & $\begin{array}{l}\text { Neutral (4) } \\
(\mathrm{n}=88)\end{array}$ & $\mathrm{F}$ & Post Hoc \\
\hline \multirow{4}{*}{ Right eye } & Upper right & $-0.11(0.23)^{* * *}$ & $-0.15(0.28)^{* * *}$ & $-0.02(0.17)$ & $-0.00(0.16)$ & $10.440^{* * *}$ & $1,3>2,4$ \\
\hline & Upper left & $-0.08(0.23)^{* * *}$ & $-0.05(0.25)$ & $-0.00(0.17)$ & $0.02(0.15)$ & $4.853^{* *}$ & $1>2,4$ \\
\hline & Lower right & $-0.01(0.22)$ & $-0.15(0.36)^{* * *}$ & $-0.06(0.19)^{* *}$ & $0.04(0.16)^{*}$ & $8.976^{* * *}$ & $3>1,4 ; 2>4$ \\
\hline & Lower left & $-0.01(0.20)$ & $-0.08(0.27)^{* *}$ & $-0.04(0.19)^{*}$ & $0.03(0.15)^{*}$ & $4.809^{* *}$ & $3>1,4 ; 2>4$ \\
\hline \multirow{4}{*}{ Left eye } & Upper right & $-0.12(0.23)^{* * *}$ & $-0.13(0.28)^{* * *}$ & $-0.02(0.18)$ & $-0.04(0.20)$ & $5.397^{* *}$ & $1,3>2$ \\
\hline & Upper left & $-0.05(0.22)^{*}$ & $-0.10(0.25)^{* * *}$ & $-0.02(0.16)$ & $-0.00(0.16)$ & $3.454^{*}$ & $3>4$ \\
\hline & Lower right & $-0.01(0.19)$ & $-0.09(0.25)^{* * *}$ & $-0.03(0.19)$ & $-0.00(0.15)$ & $4.177^{* *}$ & $3>1,4$ \\
\hline & Lower left & $0.02(0.20)$ & $-0.16(0.26)^{* * *}$ & $-0.06(0.20)^{* *}$ & $-0.00(0.15)$ & $12.591^{* * *}$ & $3>1,2,4 ; 2>1$ \\
\hline \multirow{4}{*}{ Mouth } & Upper right & $-0.14(0.28)^{* * *}$ & $-0.26(0.33)^{* * *}$ & $0.01(0.21)$ & $0.03(0.13)^{*}$ & $25.044^{* * *}$ & $3>1,2,4 ; 1>2,4$ \\
\hline & Upper left & $-0.10(0.27)^{* * *}$ & $-0.22(0.31)^{* * *}$ & $-0.03(0.21)$ & $0.03(0.14)$ & $20.717^{* * *}$ & $3>1,2,4 ; 1>2,4$ \\
\hline & Lower right & $-0.22(0.43)^{* * *}$ & $-0.21(0.35)^{* * *}$ & $-0.00(0.21)$ & $0.02(0.16)$ & $15.759^{* * *}$ & $1,3>2,4$ \\
\hline & Lower left & $-0.20(0.42)^{* * *}$ & $-0.31(0.50)^{* * *}$ & $-0.07(0.31)^{*}$ & $-0.02(0.32)$ & $9.263^{* * *}$ & $3>2,4 ; 1>4$ \\
\hline \multirow{4}{*}{ Glabella } & Upper right & $0.01(0.18)$ & $-0.05(0.24)$ & $-0.04(0.16)^{*}$ & $0.02(0.13)$ & 2.518 & \\
\hline & Upper left & $0.01(0.20)$ & $-0.06(0.25)^{*}$ & $-0.04(0.16)^{*}$ & $0.01(0.13)$ & 2.473 & \\
\hline & Lower right & $-0.12(0.20)^{* * *}$ & $-0.17(0.23)^{* * *}$ & $-0.05(0.16)^{* *}$ & $0.01(0.13)$ & $14.020^{* * *}$ & $1,3>2,4$ \\
\hline & Lower left & $-0.13(0.20)^{* * *}$ & $-0.17(0.23)^{* * *}$ & $-0.04(0.16)^{* *}$ & $-0.01(0.15)$ & $13.096^{* * *}$ & $1,3>2,4$ \\
\hline \multicolumn{2}{|l|}{ Forehead } & $-0.00(0.16)$ & $-0.13(0.36)^{* *}$ & $-0.04(0.17)^{*}$ & $0.01(0.12)$ & $7.329^{* * *}$ & $3>1,2,4$ \\
\hline \multicolumn{2}{|l|}{ Nose } & $-0.09(0.36)^{*}$ & $-0.37(0.45)^{* * *}$ & $-0.11(0.34)^{* *}$ & $0.03(0.18)$ & $19.203^{* * *}$ & $3>1,2,4 ; 2>4$ \\
\hline \multicolumn{2}{|l|}{ Left cheek } & $-0.02(0.20)$ & $-0.03(0.30)$ & $-0.02(0.16)$ & $0.03(0.16)$ & 1.303 & \\
\hline \multicolumn{2}{|l|}{ Right cheek } & $0.02(0.21)$ & $-0.06(0.32)$ & $-0.00(0.19)$ & $-0.02(0.16)$ & 1.937 & \\
\hline
\end{tabular}

Note. Mean (standard deviation)

${ }^{*} p<.05,{ }^{* *} p<.01,{ }^{* * *} p<.001$ 
화가 나타났다. 기저선에 비하여 지루함이 유발되었을 때, 위 영역의 온도가 감소하였다.

공포가 유발되었을 때에는 오른쪽 눈의 일부분(오른쪽 위 $p<.001$, 오른쪽 아래 $p<.001$, 왼쪽 아래 $p<.01$ ), 왼쪽 눈 (오른쪽 위, 왼쪽 위, 오른쪽 아래, 왼쪽 아래 모두 $p<.001$ ), 입(오른쪽 위, 왼쪽 위, 오른쪽 아래, 왼쪽 아래 모두 $p<.001$ ). 미간의 일부분(왼쪽 위 $p<.05$, 오른쪽 아래 $p$ $<.001$, 왼쪽 아래 $p<.001)$, 이마 $(p<.01)$, 코 $(p<.001)$ 영 역에서 유의한 온도 변화가 나타났다. 기저선에 비하여 공포 가 유발되었을 때, 위 영역에서의 온도가 감소하였다.

중립상태에서는 기저선에 비하여 오른쪽 눈의 일부분(오 른쪽 아래, 왼쪽 아래 모두 $p<.05$ ) 과 입의 일부분(오른쪽 위 $p<.05)$ 온도가 $0.05^{\circ} \mathrm{C}$ 미만으로 증가하였을 뿐, 기저선 에 비교한 온도 변화가 거의 없었다.

기저선에 비교하여 정서가 유발되었을 때의 얼굴 온도 변 화가 네 가지 정서상태(분노, 지루함, 공포, 중립)에 따라 다른지 검증하기 위하여 일원변량분석(one-way ANOVA) 을 수행하였으며, Tukey HSD 방법에 의한 사후검증을 실 시하였다. Table 2 에 분석결과가 제시되어 있다.

분석결과, 오른쪽 눈(오른쪽 위 $p<.001$, 왼쪽 위 $p<.01$, 오른쪽 아래 $p<.001$, 왼쪽 아래 $p<.01$ ) 과 왼쪽 눈 (오른쪽 위 $p<.001$, 왼쪽 위 $p<.05$, 오른쪽 아래 $p<.01$, 왼쪽 아래 $p<.001$ ), 입(오른쪽 위, 왼쪽 위, 오른쪽 아래, 왼쪽 아래 모두 $p<.001$ ), 미간의 일부분 (오른쪽 아래, 왼쪽 아래 모두 $p<.001)$, 이마 $(p<.001)$, 코 $(p<.001)$ 의 온도 변화가 정서 조건에 따라 다른 것으로 나타났다. 사후검증결과를 살펴보 면, 공포에서 가장 큰 온도 변화가 관찰되었으며, 다음으로 분노, 지루함, 중립의 순으로 온도 변화가 적었다.

\subsection{Emotion recognition}

눈과 입, 미간, 이마, 코, 뺨의 온도 변화로 현재의 상태가 분노, 공포, 지루함, 중립 중 어떤 상태인지를 예측하기 위한 분석을 실시하였다. 얼굴의 표정변화 변화를 반영하는 눈, 입, 미간과 정서의 변화를 반영하는 이마, 코, 뺨의 온도 변화를 모두 이용하여 선형판별분석을 실시한 결과가 Table 3에 제 시되어 있다. 평균 $62.7 \%$ (leave-one-out classification 에서는 $55.6 \%$ )의 분류정확률을 보였는데, 중립의 상태를 중립으로 예측하는 경우가 $73.9 \%$ 로 가장 높았으며, 공포를 공포로 예측하는 경우가 $51.9 \%$ 로 가장 낮았다.

얼굴의 표정 변화를 반영하는 눈, 입, 미간의 온도 변화만 을 사용하여 네 가지 정서를 분류한 결과가 Table 4 에 제시 되어 있다. 평균 $56.7 \%$ (leave-one-out classification에 서는 $47.6 \%$ )의 분류정확률을 보였는데, 중립의 상태를 중 립으로 예측하는 경우가 $64.8 \%$ 로 가장 높았고, 공포를 공
포로 예측하는 경우가 $51.9 \%$ 로 가장 낮았다.

정서상태의 변화를 반영하는 것으로 가정한 이마, 코, 뺨 의 온도 변화만을 사용하여 네 가지 정서를 분류한 결과가 Table 5에 제시되어 있다. 평균 40.2\% (leave-one-out classification에서는 $38.7 \%$ )의 분류정확률을 보였는데, 중 립을 중립으로 판단한 경우가 $60.2 \%$ 로 가장 높았고, 지루함 을 지루함으로 판단한 경우가 $22.2 \%$ 로 가장 낮았다.

Table 3. The result of LDA using facial expression and emotional state features

$(\%)$

\begin{tabular}{c|r|r|r|r|c}
\hline \multirow{2}{*}{} & \multicolumn{5}{|c}{ Predicted emotion } \\
\cline { 2 - 6 } & Anger & Boredom & \multicolumn{1}{c}{ Fear } & Neutral & Total \\
\hline Anger & 58.70 & 8.70 & 13.04 & 19.57 & 100.00 \\
\hline Boredom & 10.00 & 65.56 & 6.67 & 17.78 & 100.00 \\
\hline Fear & 18.52 & 17.28 & 51.85 & 12.35 & 100.00 \\
\hline Neutral & 4.55 & 20.45 & 1.14 & 73.86 & 100.00 \\
\hline
\end{tabular}

Table 4. The result of LDA using facial expression features

$(\%)$

\begin{tabular}{c|r|c|r|c|c}
\hline \multirow{2}{*}{} & \multicolumn{5}{|c}{ Predicted emotion } \\
\cline { 2 - 6 } & Anger & Boredom & \multicolumn{1}{c}{ Fear } & Neutral & Total \\
\hline Anger & 52.17 & 7.61 & 19.57 & 20.65 & 100.00 \\
\hline Boredom & 7.78 & 57.78 & 7.78 & 26.67 & 100.00 \\
\hline Fear & 17.28 & 16.05 & 51.85 & 14.81 & 100.00 \\
\hline Neutral & 5.68 & 20.45 & 9.09 & 64.77 & 100.00 \\
\hline
\end{tabular}

Table 5. The result of LDA using emotional state features

$(\%)$

\begin{tabular}{c|c|c|c|c|c}
\hline \multirow{2}{*}{} & \multicolumn{5}{|c}{ Predicted emotion } \\
\cline { 2 - 6 } & Anger & Boredom & Fear & Neutral & Total \\
\hline Anger & 30.43 & 10.87 & 26.09 & 32.61 & 100.00 \\
\hline Boredom & 23.33 & 22.22 & 27.78 & 26.67 & 100.00 \\
\hline Fear & 20.99 & 7.41 & 49.38 & 22.22 & 100.00 \\
\hline Neutral & 25.00 & 12.50 & 2.27 & 60.23 & 100.00 \\
\hline
\end{tabular}

세 가지 분류정확률이 통계적으로 유의하게 다른지 검증 하기 위하여 MeNemar 검증을 실시하였다(Figure 2). 검 증결과, 얼굴 표정의 변화를 반영하는 부분과 정서상태의 변화를 반영하는 부분을 모두 사용하였을 때가 얼굴 표정 의 변화를 반영하는 부분만 사용했을 때보다 분류정확률이 유의하게 높았으며 $(p<.01)$, 정서상태의 변화를 반영하는 부 
분만 사용했을 때 보다 분류정확률이 유의하게 더 높았다 ( $p<.001)$. 또한, 얼굴 표정의 변화를 반영하는 부분만 사용 했을 때가 정서상태의 변화를 반영하는 부분만 사용했을 때 보다 분류정확률이 유의하게 더 높았다 $(p<.001)$.

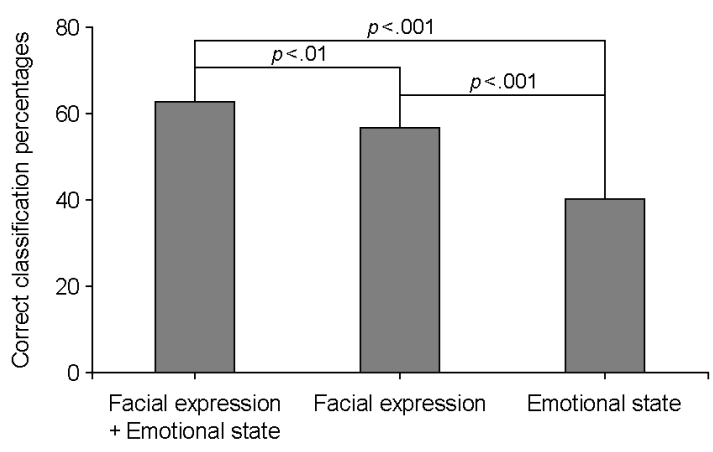

Figure 2. Correct classification percentages for each model

\section{Conclusion}

본 연구에서는 정서상태에 따라 얼굴 열영상으로 측정된 얼굴 온도가 달라지는지 확인하고, 이를 이용하여 정서를 분 류하고자 하였다. 특히, 근육의 움직임에 의한 얼굴 표정 변 화와 내적인 정서상태에 의한 얼굴온도 변화를 분리하여 각 각의 영향을 살펴보았다.

정서가 유발되었을 때의 온도 변화를 살펴본 결과, 분노 정서가 유발되었을 때에는 양쪽 눈의 위 부분과 입, 미간의 아랫부분, 코의 온도가 유의하게 감소하는 것으로 나타났다. 즉, 눈은 약간 커지고, 입은 다소 벌어졌으며, 미간을 찡그린 것이 반영된 결과이다. 공포 정서가 유발되었을 때에는 양쪽 눈과 입 미간, 이마, 코 영역에서 온도 감소가 나타났다. 즉, 눈은 커지고, 입도 벌렸으며, 미간을 찡그렸다는 의미이다. 지루함이 유발되었을 때에는 주로 미간에서 온도 변화가 뚜 렷하였으며, 코에서의 온도 변화가 나타났다. 중립상태에서 는 온도 변화가 거의 나타나지 않았다.

정서와 얼굴 온도 간의 관련성을 살펴본 선행연구들은 대 부분 특정 정서와 얼굴 온도가 관련이 있다는 사실만을 언급 하고 있으며(Yositomi, 2010; Liu \& Wang, 2011), 본 연 구에서와 같이 정서와 얼굴 온도 간 관련성이 어떻게 나타 나는지에 대한 연구는 찾아보기 어렵다.

네 가지 정서상태에 따라 얼굴 온도 변화에 차이가 있는지 살펴본 결과, 미간의 윗부분과 뺨을 제외한 나머지 영역에서 유의한 차이가 발견되었다. 눈과 입, 미간의 경우에, 공포에
서 가장 큰 온도 감소가 관찰되었으며, 다음으로 분노에서 온도 감소가 있었고, 지루함에서는 약간의 온도 감소가 있 었다. 즉, 공포 정서가 유발되었을 때 눈과 입, 미간을 포함 한 얼굴 근육이 가장 크게 움직였다는 것을 의미한다.

Ekman과 Friesen(1978)의 FACS (facial action coding system)에 따르면, 분노 정서 표현에는 $\mathrm{AU}$ (action unit) 4 (눈썹 움직임), 5 (윗눈꺼풀 움직임), 7 (눈꺼풀 움직임), 23 (입술 움직임) 번이 사용되며, 공포 정서 표현에는 1 (안쪽 눈썹 움직임), 2(바깥쪽 눈썹 움직임), 4 (눈썹 움직임), 5 (눈꺼풀 움직임), 20 (입술 움직임), 26 (아래턱 움직임) 번이 사용된다. 결과적으로 분노 정서보다 공포 정서의 표현에 더 많은 근육의 움직임이 나타나고, 이것이 공포에서 나타난 큰 온도 변화의 원인으로 해석된다.

이마와 코 영역의 경우에도, 공포 정서에서 가장 큰 온도 감소가 있었으며, 다음으로 지루함에서 온도 감소가 있었다. 분노에서는 코에서만 약간의 온도 감소가 관찰되었다. 본 연 구에서 사용한 분노와 공포 자극은 실험참여자들에게 비슷 한 수준의 정서가와 각성 수준을 유발시켰지만, 코의 온도 변화는 공포에서만 크게 나타났다.

공포상황에서 코의 온도가 감소한다는 것은 원숭이를 이 용한 연구에서 거듭 증명되었다(Kuraoka \& Nakamura, 2011). 그러나 유아를 대상으로 한 연구에서는 소리 내어 웃을 때 코의 온도가 감소함을 보고하고 있다(Nakanishi \& Imai-Matsumura, 2008). 이들은 코에서의 온도 변화는 자 율신경계의 작용에 의한 것으로 코 영역에 분포하는 혈관 때 문에 온도 변화가 나타나며, 공포와 같은 극심한 스트레스 뿐만 아니라 즐거울 때에도 동일한 작용이 나타난다고 하였 다. 공포와 소리 내어 웃는 즐거움은 모두 고 각성상태인데, 고 각성만이 코의 온도를 감소시키는 것은 아닌 것으로 보인 다. 분노와 공포 자극은 비슷한 수준의 각성을 유발시켰지만, 분노에서는 코의 온도 감소가 크지 않았기 때문이다.

공포에서 이마의 온도가 감소한 것은 선행연구와 상반된 결과이다. Pavlidis 등(2002) 과 Tsiamyrtzis 등(2007)에 따르면 스트레스 상황에서는 눈과 이마를 지나는 동정맥의 혈류량이 순간적으로 증가하여 눈 안쪽과 이마의 온도가 상 승할 것으로 예측된다. 이와 같은 본 연구와 선행연구 간의 차이는 정서의 지속시간 차이 때문인 것으로 보인다. 선행연 구들은 단지 몇 초 동안만 유지되는 스트레스에 대한 반응을 측정한 반면, 본 연구는 수십 초 이상으로 유지되는 정서에 대한 반응을 측정하였다. 그러나, 정서의 지속시간이 안면 온도에 미치는 영향은 아직 밝혀진 바가 없는 상태이다.

선형판별분석을 이용하여 근육의 움직임에 의한 온도 변 화량(눈, 입, 미간)과 정서상태에의 변화에 의한 온도 변화 량(이마, 코, 뺨)을 이용하여 네 가지 정서를 분류한 결과, 분류정확률이 $62.7 \%$ 로 나타났다. Khan 등(2006)은 기쁨, 
슬픔, 혐오, 공포, 분노, 놀람, 중립를 포함하는 여섯 가지 정 서를 $57.2 \%$ 의 정확률로, Yoshitomy (2010)는 기쁨, 슬픔, 분노, 놀람, 중립을 포함하는 다섯 가지 정서를 $80.5 \%$ 의 정 확률로 분류한 것이 비교하여 보면, 본 연구의 정확판단율이 선행연구들 보다 다소 낮은 것으로 보일 수 있다. 그러나, Khan 등(2006)과 Yoshitomy (2010)의 연구는 소수의 실 험참여자를 반복적으로 사용하였기 때문에 분류정확률이 높 게 나왔을 가능성이 높다. 더욱 중요한 것은, 이 연구들은 실험참여자로 하여금 인위적인 표정을 짓도록 하였기 때문 에, 얼굴 표정이 과장되게 나타났고, 이로 인해 분류정확률 이 높았을 가능성이 높다. 본 연구에서와 같이 유발된 정서 에서는 얼굴 표정이 크게 나타나지는 않는다. 유발 정서를 사용한 유일한 선행연구인 Liu와 Wang(2011)의 연구에서 는 기쁨, 혐오, 공포를 포함하는 세 개의 정서를 약 $60 \%$ 의 정확률로 판단했을 뿐이다.

근육의 움직임에 의한 온도 변화량만을 이용하여 네 가지 정서를 분류한 결과는 $56.7 \%$ 의 정확판단율을 보였다. 즉, 정서상태에 의한 온도 변화량이 정서변별에 기여하는 양이 $62.7-56.7=6.0 \%$ 인 것으로 나타났으며, 이 양은 통계적으 로 유의한 것이었다. 즉, 대상의 정서를 인식할 때, 근육의 움직임에 의한 온도 변화와 더불어 정서상태의 변화에 의한 온도 변화를 함께 고려하는 것이 정확판단율을 높이는 방법 이라는 것이 밝혀졌다.

본 연구의 결과는 얼굴 영상을 이용하여 대상자의 정서를 판단하기 어려운 상황에서, 얼굴 열영상을 이용하여 정서를 판단할 수 있음을 보여주었다. 더욱이, 일상생활에서 얼굴 표정을 억제하는 경향이 있는 우리나라 사람들의 특징을 감 안하면(Han, 1991), 자율신경계 반응에 의한 얼굴 온도 변 화를 정서 인식에 활용하는 것은 큰 의미를 가질 수 있다. 이러한 결과는 작업장이나 운전 등의 상황에서 응용 가능할 것으로 생각된다.

그러나, 아직까지 얼굴의 특징점(예, 눈이나 코, 입 등) 을 실시간으로 찾는 프로그램을 만들기 어렵기 때문에, 얼굴 열영상으로부터 특정위치의 온도를 실시간 추출하는 것이 어렵다. 그리고, 일반 영상을 이용한 정서 인식의 분류정확 률이 6 8개 정서에 대해 70 90\% (Pantic \& Rothkrantz, 2004; Yeasin et al., 2006)인 점에 비추어 보면, 아직까지 열영상을 이용한 정서 인식의 분류정확률은 다소 낮은 편이 다. 이러한 점들이 본 연구의 결과를 실제 현장에 활용하는 데 있어서 한계점으로 작용할 것이다.

\section{Acknowledgements}

This research was supported by the Converging Research Center Program funded by the Ministry of Education, Science and Technology(No. 2011K000658).

\section{References}

Arnett, J., Offer, D. \& Fine, M. A., Reckless driving in adolescence: 'state' and 'trait' factors, Accident Analysis and Prevention, 29, 57-63, 1997.

Banuls, R., Carbonell Vaya, E., Casanoves, M. \& Chisvert, M., Different emotional responses in novice and professional drivers. In Traffic and transport psychology: Theory and application. In Proceedings of the international conference on traffic psychology, 343-352, Valencia, Spain, 1996.

Bartlett, M. S., Littlewort, G., Frank, M. G., Lainscsek, C., Fasel I. \& Movellan., J., Fully Automatic Facial Action Recognition in Spontaneous Behavior, Proc. IEEE Int'l Conf. Automatic Face and Gesture Recognition (AFGR '06), 223-230, 2006.

Chang, Y., Hu, C., Feris, R. \& Turk., M., Manifold Based Analysis of Facial Expression, Journal of Image and Vision Computing, 24 (6), 605-614, 2006.

Chen, Z., Ma, L. \& Sen, Y., Behavioural approaches to safety management in underground mines, In proceedings of the international conference of information technology, computer engineering and management sciences, 324-327, Nanjing, China, 2011.

Cohn, J. F., Foundations of Human Computing: Facial Expression and Emotion. Proc. Eighth ACM Int'l Conf. Multimodal Interfaces (ICMI '06), 233-238, 2006.

Deffenbacher, J. L., Lynch, R. S., Oetting, E. R. \& Yingling, D. A., Driving anger: Correlates and a test of state-trait theory, Personality and Individual Differences, 31, 1321-1331, 2001.

Ekman, P. \& Friesen, W., Facial Action Coding System: A technique for the measurement of facial movement. Consulting Psychologists Press, Palo Alto, 1978.

Eyben, F., Wollmer, M., Graves, A., Schuller, B., Douglas-Cowie, E. \& Cowie, R., On-line emotion recognition in a 3-D activation-valencetime continuum using acoustic and linguistic cues, Journal of Multimodal user interfaces, 3, 7-19, 2010.

Fisher, C. D. \& Ashkanasy, N. M., The emerging role of emotions in work life: An introduction, Journal of Organizational Behavior, 21, 123 $-129,2000$.

Gross, J. J. \& Levenson, R. W., Emotion elicitation using films. Cognition and Emotion, 9, 87-108, 1995.

Han, G. S., Cultural limitations of social psychological theories: A review for the social psychology of Korean people, Korean Journal of Social Psychology, 6, 132-155, 1991. 
Jarlier, S., Grandjean, D., Delplanque, S., N'Diaye, K., Cayeux, L., Velazco, M. L., Sander, D., Vuilleumier, P. \& Scherer, K. R., Thermal analysis of facial muscles contractions, IEEE Transactions on Affective Computing, 2, 2-9, 2011.

Katsis, C. D., Katertsidis, N., Ganiatsas, G. \& Fotiadis, D. I. Toward emotion recognition in car-racing drivers: A biosignal processing approach, IEEE Transactions on Systems, Man and Cybernetics, Part A: Systems and Humans, 38, 502-512, 2008.

Khan, M. M., Ingleby, M. \& Ward, R. D., 2006, Automated facial expression classification and affect interpretation using infrared measurement of facial skin temperature variations, ACM Transactions on Autonomous and Adaptive Systems, 1, 91-113, 2006.

Kim, K., Bang, S. \& Kim, S., Emotion Recognition System Using ShortTerm Monitoring of Physiological Signals, Medical and Biological Engineering and Computing, 42, 419-427, 2004.

Kuraoka, K. \& Nakamura, K., The use of nasal skin temperature measurements in studying emotion in macaque monkeys, Physiology \& Behavior, 102, 347-355, 2011.

Liu, C., Conn, K., Sarkar, N. \& Stone, W., Physiology-Based Affect Recognition for Computer-Assisted Intervention of Children with Autism Spectrum Disorder, International Journal of Human-Computer Studies, 66, 662-677, 2008.

Liu, Z. \& Wang, S., Emotion recognition using hidden markov models from facial temperature sequence, Affective Computing and Intelligent Interaction, Lecture Notes in Computer Science, 6975, 240-247, 2011.

Loukidou, L., Loan-Clarke, J. \& Daniels, K., Boredom in the workplace: More than monotonous tasks, International Journal of Management Reviews, 11, 384-405, 2009.

Merla, A. \& Romani, G. L., Thermal signatures of emotional arousal: A functional infrared imaging study, In Proceedings of the Annual International Conference of the IEEE EMBS, Lyon, Frace, 23-26, 2007.

Nakanishi, R. \& Imai-Matsumura, K., Facial skin temperature decreases in infants with joyful expression, Infant behavior \& Development, 31, 137-144, 2008.

Nasoz, F., Alvarez, K., Lisetti, C. L. \& Finkelstein, N., Emotion recognition from physiological signals using wireless sensors for presence technologies, Cognitive, Technology \& Work, 6, 4-14, 2004.

Nhan, B. R. \& Chau, T., Classifying affective states using thermal infrared imaging of the human face, IEEE Transactions on Biomedical Engineering, 57, 979-987, 2010.

Pantic, M. \& Bartlett, M. S. (2007). Machine Analysis of Facial Expressions, Face Recognition, In K. Delac and M. Grgic (Eds.), 377-416, I-Tech Education and Publishing.

Pantic, M. \& Rothkrantz, L. J. M., Facial action recognition for facial expression analysis from static face images, IEEE Transactions on Systems, Man, and Cybernetics Part B, 34, 1449-1461, 2004.

Parvlidis, I., Eberhardt, N. L. \& Levine, J. A. Seeing through the face of deception, Nature, 415, 35, 2002.

Picard, R. W., Vyzas, E. \& Healey, J., Toward Machine Emotional Intelligence: Analysis of Affective Physiological State, IEEE Transactions on
Pattern Analysis and Machine Intelligence, 23(10), 1175-1191, 2001.

Rimm-Kaufmann, S. E. \& Kagan, J., The psychological significance of changes skin temperature, Motivation and Emotion, 20, 63-78, 1996.

Shami, M. \& Verhelst, W., An evaluation of the robustness of existing supervised machine learning approaches to the classification of emotion in speech, Speech Communication, 49(3), 201-212, 2007.

Trujillo, L., Olague, G., Hammoud, R. \& Hernandez, B., Automatic feature localizations in thermal images for facial expression recognition, In Proceedings of the IEEE Computer Society Conference on Computer Vision and Pattern Recognition, 14-14, 2005.

Tsiamyrtzi, P., Dowdall, J., Shastri, D., Pavlidis, I. T., Frank, M. G., Ekman, P., Imaging facial physiology for the detection of deceit, International Journal of Computer Vision, 71, 197-214, 2007.

Yeasin, M., Bullot, B. \& Sharma, R., Recognition of facial expressions and measurement of levels of interest from video, IEEE Transactions on Multimedia, 8, 500-507, 2006.

Yoshitomi, Y., Facial expression recognition for speaker using thermal image processing and speech recognition system, In Proceedings of the WSEAS International Conference on Applied Computer Science, Athens, Greece, 182-186, 2010.

Zeng, Z., Pantic, M., Roisman, G. I. \& Huang, T. S., A survey of affect recognition methods: Audio, visual, and spontaneous expressions, IEEE Transactions of Pattern Analysis and Machine Intelligence, 31, 39-58, 2009.

\section{Author listings}

Jin-Sup Eom: jseom2003@hanmail.net

Highest degree: $\mathrm{PhD}$, Department of psychology, Chungbuk National University

Position title: Researcher, Brain Research Institute, Chungnam National University

Areas of interest: Psychometrics, Statistics, Lie Detection

Jin-Hun Sohn: jhsohn@cnu.ac.kr

Highest degree: PhD, Department of psychology, the University of Korea Position title: Professor, Department of Psychology, Chungnam National University

Areas of interest: Brain Science, Neuroscience, Electro Physiology

Date Received : 2012-03-14

Date Revised :2012-05-10

Date Accepted : 2012-05-11 